\title{
MODELING OF BEE-BREAD DRYING PROCESS
}

\author{
Sergey Kharchenko, Sergei Oskin, Dmitry Tsokur \\ Kuban State Agrarian University named after I.T. Trubilin, Russia \\ ser.harchenko1995@yandex.ru,kgauem@yandex.ru,dmitry_tsokur@mail.ru
}

\begin{abstract}
Drying of bee-bread is an important technological process, which determines the quality of the product produced. Drying of bee-bread is carried out in conditions that prevent the occurrence of irreversible changes in the product, which can lead to deterioration of its quality. These changes are largely associated with the processes of denaturation of proteins and inactivation of enzymes caused by heating of bee-bread during drying at temperatures above $40^{\circ} \mathrm{C}$. Analysis of literature sources has shown that bee-bread is dried mainly either by convection or vacuum drying. Sometimes these drying methods are combined with infrared heating. The disadvantage of the convection drying method is the high energy intensity of the process. The disadvantage of the vacuum method is the high cost of equipment, so it cannot be recommended for small businesses. To reduce the drying time and energy intensity of the process, it is possible to add infrared heating to the main drying methods. But to date, parameters and modes of operation of such a technological process are not defined, which makes it difficult to use it in agriculture. The article presents the results of modeling the joint use of convection and infrared methods of drying bee-bread in the device focused on small businesses. Simulation of the combined drying process was carried out in the program Comsol Multiphysics 5.4. The resulting mathematical model allows determining parameters and modes of the process of drying bee-bread without losing the quality of the product.
\end{abstract}

Keywords: bee-bread, convection drying, Comsol Multiphysics, infrared drying, modeling.

\section{Introduction}

In order to increase the profitability of production and create favorable conditions for the development of small businesses in Russia, it is necessary to introduce inexpensive and energyefficient technologies for processing agricultural products.

At present, beekeeping in Russia is in difficult financial conditions. This is primarily due to the use of outdated technologies for beekeeping and low use of primary processing of products. Therefore, the development of new environmentally friendly and low cost technologies for beekeeping product processing is an important task for the Russian agro-industrial complex.

Now beekeepers are starting to use the packaging of the resulting products, conservation, processing of certain types of products and partially engaging in sales. One of the energy-consuming types of processing is drying of bee-bread and pollen. Often, in small forms of management, drying is carried out by the convection method. With this method of drying the energy costs can be $11.89 \mathrm{kWh} \cdot \mathrm{kg}^{-1}$ [1]. The energy intensity of the process depends largely on the capacity of the electric heater and the initial humidity of the product. In a plant without heat transfer medium recovery, the installed power can reach 10-15 kW. It is known from literature sources that recuperation reduces the energy intensity of the process, but increases the duration of drying. The use of vacuum drying or its combination with convection drying significantly increases the price of the plant and, accordingly, the cost of production. Besides, researches, in which destructive influence of vacuum drying on bee-bread in comparison with convective drying was indicated, are known [2]. Thus, the study of the issue of reducing the energy consumption and drying time is an actual task. It is possible to solve this problem by a combination of convective and infrared drying. It is necessary to note that many researches were devoted to researching of drying of these or those products, but till now the mathematical model of drying of bee-bread by means of a combination of convective and infra-red drying is not developed [715]. In order not to waste resources and time on development of dryer prototypes and determination of optimal modes of operation, it is necessary, first of all, to develop a model of a dryer unit, to conduct its mathematical processing; this is what this article is devoted to.

\section{Materials and methods}

The object of the study was a convection dryer used in peasant (farm) households of the Krasnodar Territory of the Russian Federation (Fig. 1, left). It is proposed to simulate the process of drying bee-bread in Comsol Multiphysics software product. Initially, in this software a geometric model of the object was developed. Then, the following calculation interfaces were chosen: Laminar 
Flow, Heat transfer, Transport of Diluted Species [5; 6]. To reduce the calculation time, half of the drying plant was simulated (Fig. 1, right). The automation system was not included in the geometric model.

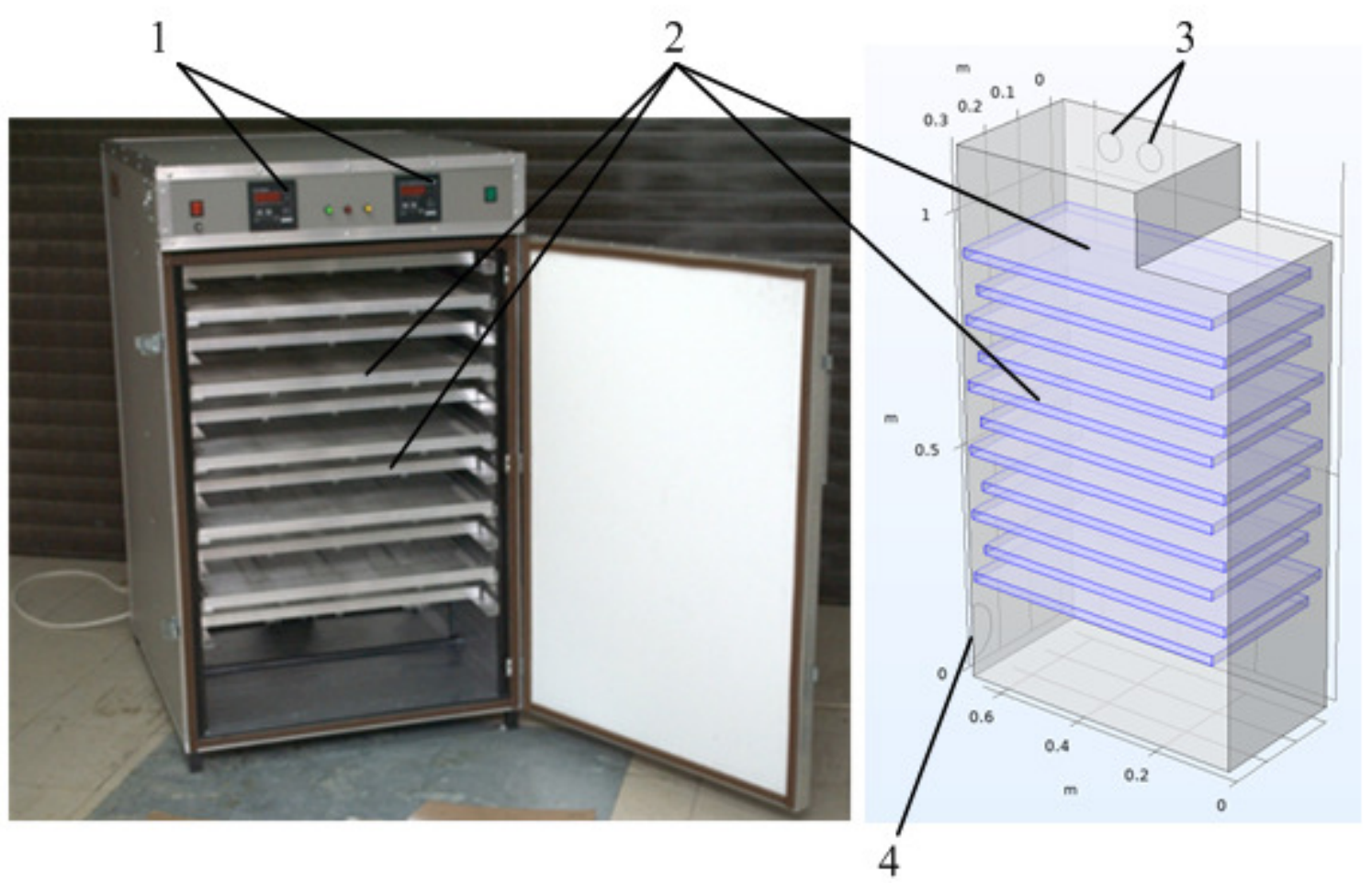

Fig. 1. Photo of the convection dryer (left) and its geometrical model in Comsol Multiphysics (right): 1 - automation system; 2 - trays with bee-bread; 3 - holes for the heat transfer medium outlet; 4 - hole for the heat transfer medium inlet

Bee-bread in the model is represented as a porous structure. The following is accepted as boundary conditions: the inner walls of the drying chamber are covered with heat-insulating material (absence of heat transfer to the external environment), the initial relative moisture content in bee-bread is 0.24 ; the relative humidity of the air entering the unit is 0.3 ; the air velocity at the inlet is $1.5 \mathrm{~m} \cdot \mathrm{s}^{-1}$; the power of the inlet air heater is $400 \mathrm{~W}$; the inlet air temperature is $20^{\circ} \mathrm{C}$; the mass density of beebread is $650 \mathrm{~kg} \cdot \mathrm{m}^{-3}$; the heat capacity and thermal conductivity of the materials is taken from the reference books. The weight of bee-bread loaded into the unit is $54.3 \mathrm{~kg}$. Thus, in the model there is no heat exchange with the environment and the insulation condition is applied to the walls of the chamber.

As an example of solving a similar problem, the model of drying a porous body described in [3] was used. The following limitation is used to account for liquid and gaseous phases:

$$
S_{g}+S_{l}=1,
$$

where $S_{g}$ - gaseous phase saturation, relative units;

$S_{l}-$ liquid phase saturation, relative units.

$$
S_{l}=\frac{c_{w} M_{w}}{\rho_{w} \varepsilon},
$$

where $c_{w}$-moisture concentration in bee-bread, $\mathrm{mol} \cdot \mathrm{m}^{-3}$;

$M_{w}-$ molar weight of water, $\mathrm{kg} \cdot \mathrm{mole}^{-1}$;

$\rho_{w}$ - water density, $\mathrm{kg} \cdot \mathrm{m}^{-3}$;

$\varepsilon$ - porosity of bee-bread in the trays ( 0.5 in the model).

The concentration of moisture in bee-bread $c_{w}$ was determined using the Transport of Diluted Species interface [5]: 


$$
\begin{gathered}
\frac{\partial c_{w}}{\partial t}+\nabla \cdot J_{w}+u \cdot \nabla c_{w}=R_{w}, \\
J_{w}=-D_{w} \nabla c_{w},
\end{gathered}
$$

where $D_{w}-$ diffusion coefficient, $\mathrm{m}^{2} \cdot \mathrm{s}^{-1}$;

$R_{w}$ - reaction rate, $\mathrm{mol} \cdot\left(\mathrm{m}^{3} \cdot \mathrm{s}\right)^{-1}$

$u$ - mass averaged velocity vector, $\mathrm{m} \cdot \mathrm{s}$;

$J_{w}$ - mass flux, $\mathrm{mol} \cdot\left(\mathrm{m}^{2} \cdot \mathrm{s}\right)^{-1}$.

The velocities of the thermal transfer medium inside the drying chamber are described using the Navier-Stokes equations. All the physical interfaces used in the program were connected to each other via the Multiphysics unit. The simulation was carried out in 2 steps: the first step was to calculate the stationary field of velocities of the thermal transfer medium inside the plant, and the second step was to calculate the non-stationary heat and mass transfer.

\section{Results and discussion}

Initially, the drying process was simulated by means of convective heat exchange only. The relative humidity of bee-bread according to Russian standards should not exceed 0.15 [4]. According to the results obtained, after 10 hours the lower half of the trays with bee-bread (tray1-tray5) already reaches the required humidity. By 15 hours of drying, the maximum moisture content in the upper trays was 0.13 (Fig. 2).

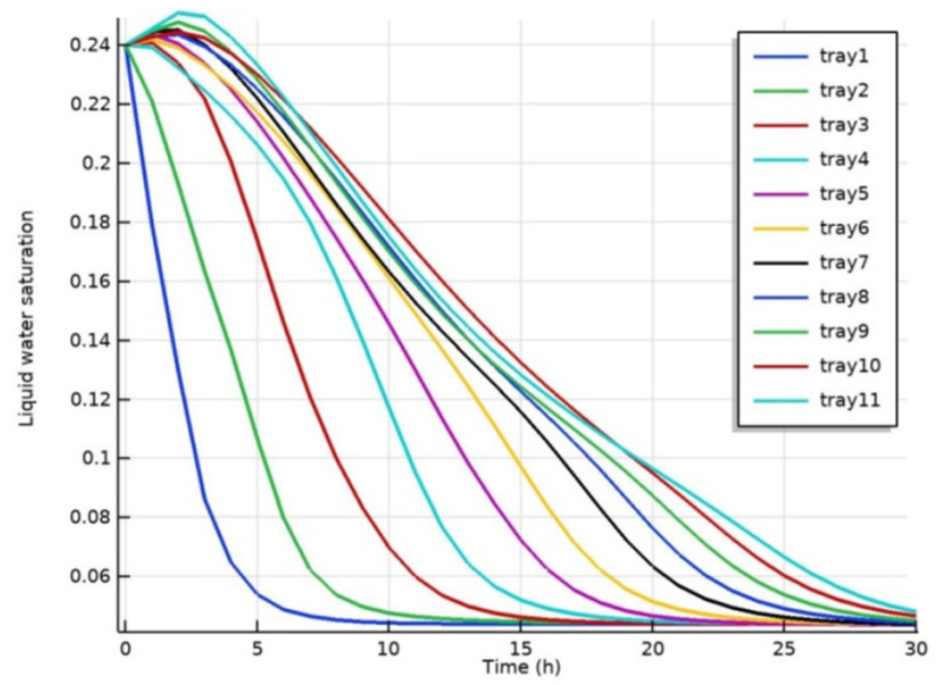

Fig. 2. Change in average moisture content within the framework of convection drying with bee-bread

The highest thermal transfer medium velocities are at the bottom of the drying chamber, from 0.7 to $1.5 \mathrm{~m} \cdot \mathrm{s}^{-1}$ (Fig. 3, left). Due to the zigzag arrangement of the trays, part of the coolant flow blows the surface of the bee-bread. The other part of the thermal transfer medium flows along the walls of the drying chamber and interacts weakly with the trays. The left and right parts of the drying chamber (Fig. 3, left) are blown unevenly. Most of the thermal transfer medium flow is concentrated on the left. This can be clearly seen from the speeds in the upper left part of the drying chamber, where the flow rate is $0.18 \mathrm{~m} \cdot \mathrm{s}^{-1}$.

Further, a simulation of the joint use of convection and infrared drying methods was performed. The drying chamber side opposite the inlet opening was covered with an infrared film heater (Fig. 3, right). The total power of the film heater was $30 \mathrm{~W}$ with radiation intensity from $180 \mathrm{~W} \cdot \mathrm{m}^{2}$ to $190 \mathrm{~W} \cdot \mathrm{m}^{2}$. The power of the heater at the input was reduced to $300 \mathrm{~W}$. Such reduction was made on the basis of several iterations of calculation with control of humidity and temperature of bee-bread. At full coincidence of the moisture content curves in the trays (Fig. 2), the inlet air heating power was set to $300 \mathrm{~W}$. 
Time $=30 \mathrm{~h} \quad$ Contour: Velocity magnitude $(\mathrm{m} / \mathrm{s})$ Streamline: Velocity field Surface: Velocity magnitude $(\mathrm{m} / \mathrm{s}$

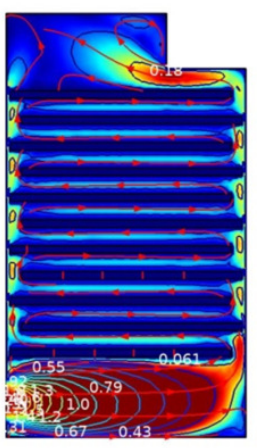

Time $=30 \mathrm{~h} \quad$ Surface: Wall blackbody radiation intensity $\left(\mathrm{W} /\left(\mathrm{m}^{3} * \mathrm{rr}\right)\right)$

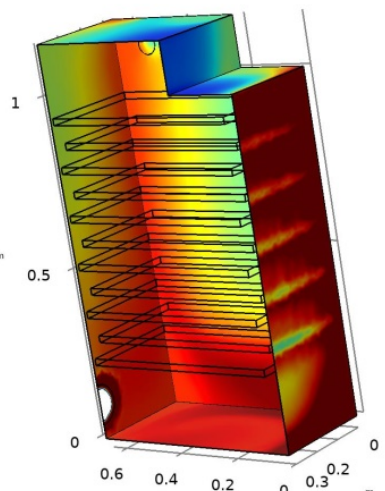

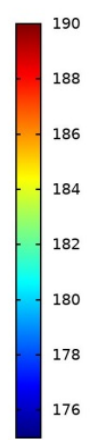

Fig. 3. Air velocities inside the drying chamber (left), radiated intensity of the drying chamber walls (right)

The analysis of the temperature changes of individual trays (Fig. 4), in time, showed the following. In the absence of an infrared heater, the time to reach the set temperature is about 3 hours (Fig. 4, left). Whereas with infrared heating, to the set temperature mode the frames leave after 10 hours (Fig. 4, right).
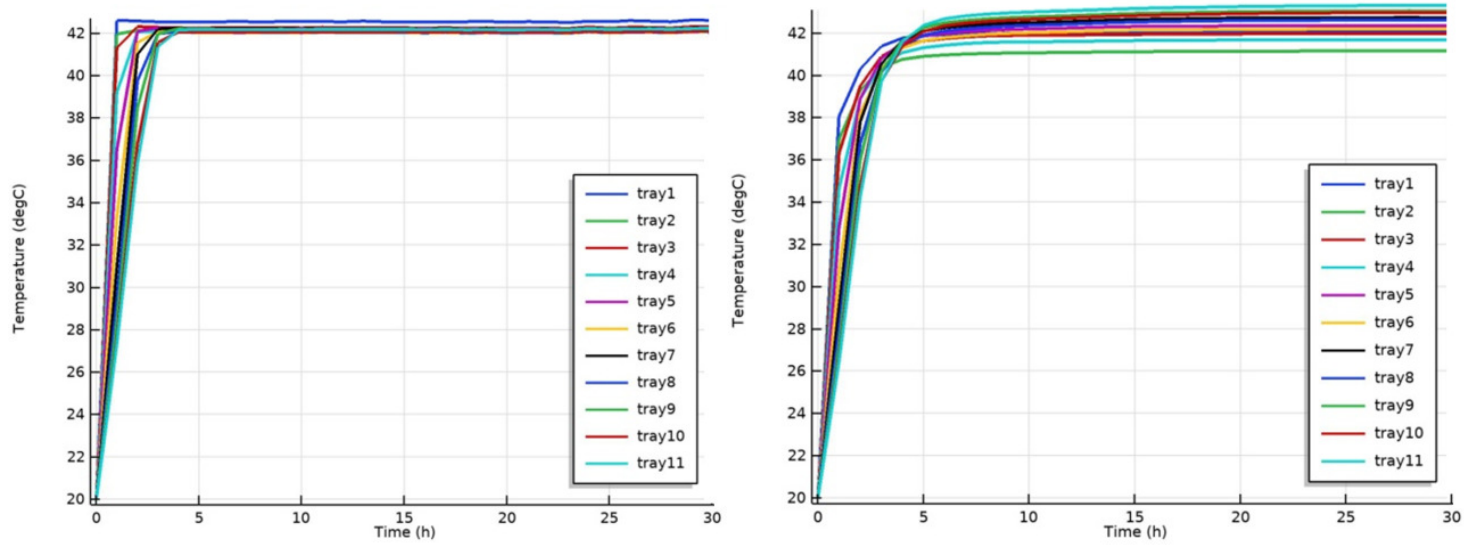

Fig. 4. Changes in the average temperature of trays with bee-bread during convective drying (left) and during a combination of convective and infrared drying (right)

The study of the temperature fields inside the drying chamber showed a great unevenness of temperature distribution in cases of infrared irradiation (Fig. 5). This irregularity is explained by the lower value of the input air heating power. However, this did not affect the drying speed and it remained the same as in Fig. 2.

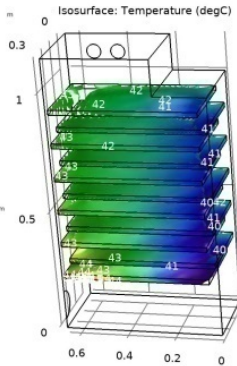

a)



b)

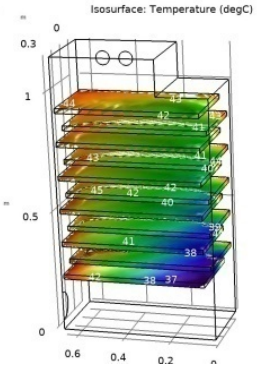

c)

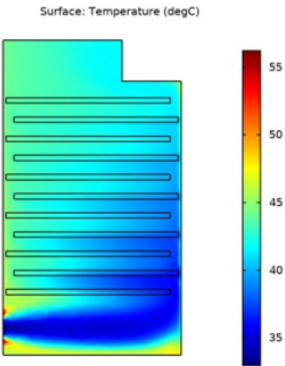

d)

Fig. 5. Type of temperature fields: without IR heating (a, b) and with IR heating (c, d) 


\section{Conclusions}

The developed model of bee-bread drying takes into account the geometric dimensions of the drying chamber and the trays with the product, the thermal and physical properties of air and beebread. It allows obtaining fields of speed, temperature and humidity during convection and infrared drying.

The use of infrared heating together with the convection drying method allowed to reduce the plant power from $400 \mathrm{~W}$ to $330 \mathrm{~W}$. Thus, the specific energy of the technological process has been reduced from $111 \mathrm{~W} \cdot \mathrm{kg}^{-1}$ to $91 \mathrm{~W} \cdot \mathrm{kg}^{-1}$, which proves the efficiency of IR heating. It is worth noting the uneven drying time of each of the trays with bee-bread. The drying time of the lower four trays is up to 10 hours. By 15 hours, when the moisture content of the upper trays is between 0.1 and 0.13 , the lower trays are already significantly dry and the moisture content is below 0.06 . To solve this problem, it is necessary to change the design of the drying chamber or trays.

Thus, this model makes it possible to determine rational structural (geometric dimensions of the drying chamber, distance from heaters to the product trays, etc.), as well as technological (air velocity at the inlet, drying time, power of heaters) parameters of the plant from the point of view of intensification of the process of bee-bread drying.

\section{References}

[1] Vinokurov S.V. Technology and installation for drying bee-bread in honeycomb. PhD Eng. thesis. Ryazan: RSATU, 2002. 196 p.

[2] Kashirin D.E. Convective drying of bee-bread. Magazine Apiculture, 2009, No 8. pp 46-47.

[3] Evaporation in Porous Media with Large Evaporation Rates. Model from application gallery of Comsol. [online][11.02.2020] Available at: https://www.comsol.com/model/evaporation-inporous-media-with-large-evaporation-rates-33731

[4] Technical specifications 10 RF 505-92 Dried bee-bread. 1992. 19 p. (In Russian).

[5] CFD Module User's Guide. COMSOL.

[6] Heat Transfer Module User's Guide. COMSOL.

[7] Aboltins, A. Theoretical study of material drying coefficient; Proceedings of International scientific conference "Engineering for Rural Development", Latvia University of Agriculture, Jelgava, 2013, pp. 153-158.

[8] Aboltins A., Upitis A. Experimental and theoretical investigation of agricultural material drying process. Proceedings 11th International Scientific Conference "Engineering for Rural Development", Jelgava: LLU, 2012. pp. 93-98.

[9] Kic P., Aboltins A. Convective drying of poultry manure by different air speeds.: Proceedings 12th International Scientific Conference "Engineering for Rural Development", Jelgava, LLU, 2013, pp. 121-125.

[10] Rubina T., Aboltins A., Palabinskis J. Drying characteristics of rhubarb cubes at low temperature. 8th International Scientific Conference Engineering for Rural Development, Jelgava: LLU, 2019. pp. 1249-1256.

[11] Aboltins A., Palabinskis J., Vartukapteinis K. Studies of berry drying process in infrared film dryer. Proceeding of the International Scientific Conference Engineering for Rural Development, Latvia University of Agriculture, Jelgava, Latvia, 2017. pp. 1515-1520.

[12] Aboltins A., Palabinskis J. Fruit drying process investigation in infrared film dryer. Agronomy research, Vol. 14(1), 2016. pp. 5-13.

[13] Aboltins A., Upitis A. Mathematical model of carrot drying. Proceeding of the International Scientific Conference Engineering for Rural Development, Latvia University of Agriculture, Jelgava, Latvia, 2011. pp. 88-92.

[14] Rudobashta S., Zueva G., Zuev N. Mathematical Modeling and Numerical Simulation of Seeds Drying Under Oscillating Infrared Irradiation. Drying Technology, 2014, 32(11). pp. 1352-1359.

[15] Jain, D., Pathare, P. B. Selection and Evaluation of Thin Layer Drying Models for Infrared Radiative and Convective Drying of Onion Slices. Biosystems Engineering, 89(3). pp. 289-296. 